\title{
Assessment of XM-19 as a Substitute for AISI 348 in ATR Service
}

\author{
F. A. Garner \\ L. R. Greenwood \\ R. E. Mizia \\ C. R. Tyler
}

November 2007

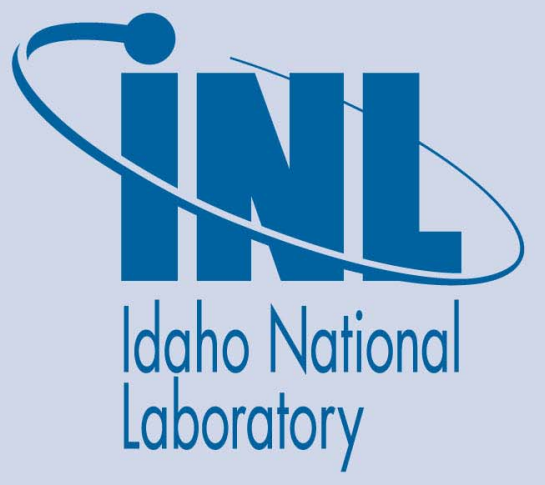

The INL is a U.S. Department of Energy National Laboratory operated by Battelle Energy Alliance 
INL/EXT-07-13530

\title{
Assessment of XM-19 as a Substitute for AISI 348 in ATR Service
}

\author{
F. A. Garner ${ }^{1}$ \\ L. R. Greenwood ${ }^{1}$ \\ R. E. Mizia ${ }^{2}$ \\ C. R. Tyler ${ }^{2}$ \\ ${ }^{1}$ Pacific Northwest National Laboratory \\ ${ }^{2}$ Idaho National Laboratory \\ November 2007

\section{Idaho National Laboratory \\ Idaho Falls, Idaho 83415} \\ Prepared for the \\ U.S. Department of Energy \\ Office of Nuclear Energy \\ Under DOE Idaho Operations Office \\ Contract DE-AC07-05ID14517
}




\section{DISCLAIMER}

This information was prepared as an account of work sponsored by an agency of the U.S. Government. Neither the U.S. Government nor any agency thereof, nor any of their employees, makes any warranty, expressed or implied, or assumes any legal liability or responsibility for the accuracy, completeness, or usefulness, of any information, apparatus, product, or process disclosed, or represents that its use would not infringe privately owned rights. References herein to any specific commercial product, process, or service by trade name, trade mark, manufacturer, or otherwise, does not necessarily constitute or imply its endorsement, recommendation, or favoring by the U.S. Government or any agency thereof. The views and opinions of authors expressed herein do not necessarily state or reflect those of the U.S. Government or any agency thereof. 



\section{SUMMARY}

It has been proposed that XM-19 alloy be considered as a possible replacement steel for AISI 348 in the construction of Advanced Test Reactor (ATR) capsules. AISI 348 works well, but is currently very difficult to obtain commercially.

The superior and desirable mechanical properties of XM-19 alloy have been proven in non-nuclear applications, but no data are available regarding its use in radiation environments. While most 300 series alloys will meet the conditions required in ATR, it cannot be confidently assumed that XM-19 can be substituted without prior qualification in a radiation test.

Compared to AISI 348, XM-19 will have an enhanced tendency for phase instabilities due to its higher levels of $\mathrm{Ni}$ and, especially, Si. However, transmutation of important elemental components in the highly thermalized ATR spectrum may have a very pronounced effect on its performance during irradiation.

Not only will strong transmutation of Mn to Fe reduce the ductility and strength advantages provided by the higher initial Mn content of XM-19, but the extensive loss of $\mathrm{Mn}$ will also release from solution much of the $\mathrm{N}$ upon which the higher strength of XM-19 depends. In addition, the combined influence of transmutation and Inverse Kirkendall processes may lead to gas-bubble-covered grain boundaries, producing a very fragile alloy after significant irradiation has accumulated. At present, there are no radiation data available to substantiate this possible scenario.

An alternate proposal is therefore advanced. Since the response of AISI 348 and 347 to radiation are expected to be relatively indistinguishable, the AISI 347 might serve as an acceptable replacement. While AISI 348 is usually chosen for nuclear service in order to reduce the overall radioactivity arising from relatively small amounts of highly transmutable elements such as cobalt, these elements have very little effect on the radiation performance of the steel. In the proposed application, however, the activity induced in this highly thermalized spectrum to large doses (10 to $50 \mathrm{dpa}$ ) will be overwhelmed by the activation arising from the major steel components: $\mathrm{Fe}, \mathrm{Cr}$, and especially Ni. The mechanical properties, irradiation creep, and void swelling behavior of the two steels should be practically indistinguishable. 


\section{CONTENTS}

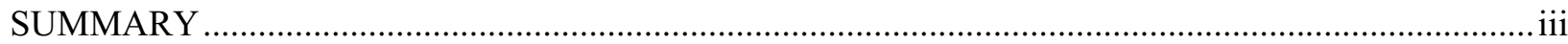

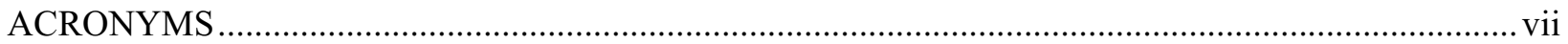

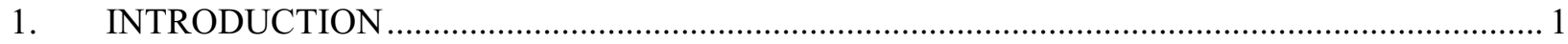

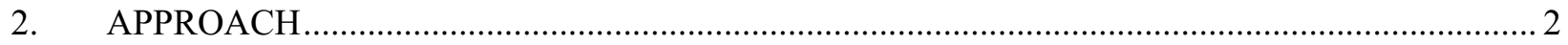

3. Comparison of AISI 347/348 with other 300 Series Stainless Steels ............................................ 2

3.1 Advantages of XM-19 (Nitronic 50) Stainless Steel........................................................... 4

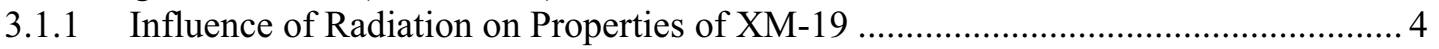

3.1.2 Influence of Transmutation on the Composition of XM-19 ….............................. 5

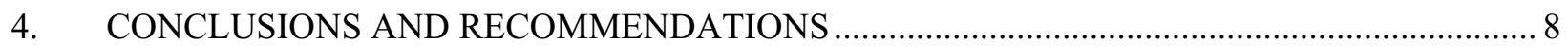

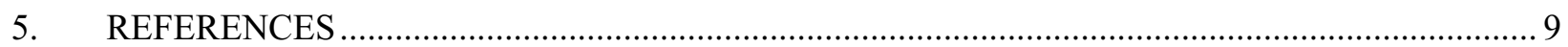

\section{FIGURES}

Figure 1. Generation of high levels of helium and hydrogen in XM-19 as a function of neutron

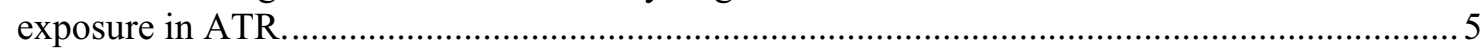

Figure 2. Decline in Mn content in XM-19 with accumulated neutron exposure in ATR........................ 6

Figure 3. Gas-filled bubbles observed by electron microcopy in cold-worked 316 stainless steel after irradiation in a commercial PWR to $70 \mathrm{dpa}$ at $350^{\circ} \mathrm{C}^{31}{ }^{31}$............................................. 7 


\section{ACRONYMS}

AISI American Iron and Steel Institute

ATR Advanced Test Reactor

HFIR High Flux Isotope Reactor

INL Idaho National Laboratory

ITER International Thermonuclear Experimental Reactor

LMR Liquid Metal Reactor

LWR Light Water Reactor 


\section{Assessment of XM-19 as a Substitute for AISI 348 in ATR Service}

\section{INTRODUCTION}

The 300 series stainless steel AISI 348 has been used as a structural steel in the construction of experimental assemblies for the Advanced Test Reactor (ATR) located at Idaho National Laboratory (INL). However, due to difficulties in obtaining AISI 348, XM-19 or Nitronic 50 (also a 300 series stainless steel) is being considered as a replacement material for use in future assemblies. In the unirradiated condition, XM-19 has mechanical properties that are considered superior to those of AISI 348 , properties that would allow less stringent tolerances in assembly design.

The designers of the International Thermonuclear Experimental Reactor (ITER), a fusion reactor, are also considering the use of XM-19 as a replacement for AISI 316, but only for maximum doses of 3-5 dpa (displacement per atom) and at temperatures of $<120^{\circ} \mathrm{C}$. The ITER spectrum is not as thermalized as that of ATR.

The ideal situation for assessing such a replacement scenario for ATR application would involve a side-by-side, one-on-one comparison of the response of these two steels to radiation exposure. Unfortunately, such data are not currently available. A relatively scarce amount of published data addressing lower exposure levels on AISI 348 are available, ${ }^{1,2,3}$ but the majority of data addressing higher doses generated in ATR are not openly published. Even more importantly, no published data are available on the response of XM-19 to radiation exposure. Although this steel has been used in various small components of Light Water Reactors (LWRs) within last decade, no examination of these components has been reported. ${ }^{4}$

Since the composition of XM-19 differs significantly from that of AISI 348, there is a concern that its radiation performance will also differ significantly with respect to phase stability, gas generation rates, and retention of desirable properties.

Faced with the lack of XM-19 irradiation data, the suggested approach to assess its use as a replacement for AISI 348 is to answer the following questions:

- Since the radiation performance of the XM-19 steel is as important or more important than its starting properties, how can its potential performance under radiation be estimated?

- Is the anticipated radiation performance specific to the neutron flux-spectra characteristic of ATR?

- If the uncertainties associated with XM-19 preclude its confident use, are there other better qualified candidates such as 347 and 316 steels, which have much larger published data bases?

- Is it possible to gain new data on the radiation performance of XM-19 in a relatively short time?

This report answers these questions by assessing the potential of using XM-19 as a substitute for AISI 348 in ATR service. Other 300 series stainless steels are also considered in this study. 


\section{APPROACH}

The following actions were taken during this assessment:

1. Reviewed the operating environment and target exposures envisioned for ATR application.

2. Reviewed previously unpublished reports supplied by INL on the radiation response of AISI 348 in ATR.

3. Determined the compositional and metallurgical origins of the superior performance of XM-19 in non-nuclear applications.

4. Using INL-supplied flux-spectra, calculated the anticipated transmutation of XM-19 to ascertain if the compositional origins of the desirable properties might be strongly changed.

5. Reviewed the interaction of compositional and environmental conditions to assess the potential for phase instabilities that might adversely impact material performance.

6. Based on the above actions, provided suggestions on further efforts involving XM-19 or other candidate steels.

The following exposure conditions relevant to this study were supplied by INL:

- Maximum fluence limit: $4 \times 10^{22} \mathrm{n} / \mathrm{cm}^{2}, \mathrm{E}>1 \mathrm{MeV}$

- Temperature Range: 240 to $930^{\circ} \mathrm{F}$, with an in-core average of $<800^{\circ} \mathrm{F}$ and an in-core maximum wall temperature of $870^{\circ} \mathrm{F}$.

For the purposes of this study, this translates roughly into boundaries of 0 to $70 \mathrm{dpa}$ and 115 to $466^{\circ} \mathrm{C}$. These are high doses for the steels under consideration in this report, but relatively low temperatures with respect to potential phase instabilities, especially those of the intermetallic type. Radiation-stable phases usually predominate in this temperature range, with gamma prime competing with G-phase. The latter phase is promoted by higher levels of $\mathrm{Mn}, \mathrm{Cr}$, and small amounts of $\mathrm{Nb}$ and $\mathrm{V}$ and has been observed in AISI 348 irradiated in ATR.

The flux-spectral characteristics supplied by INL were used to determine the dpa levels and the transmutation rates. The neutron exposures and the derived transmutation rates are provided in the attached spread sheet.

Based on INL-supplied flux-spectra, $1 \times 10^{22} \mathrm{n} / \mathrm{cm}^{2}(\mathrm{E}>1.0 \mathrm{MeV})=17.5 \mathrm{dpa}$.

Fluence $>0.1 \mathrm{MeV}$ is $28.8 \%$ of the total.

Fluence $>1.0 \mathrm{MeV}$ is $14.4 \%$ of the total.

The calculations performed in this study were based on an assumed total flux of $1.00 \mathrm{E} 15 \mathrm{n} / \mathrm{cm}^{2} / \mathrm{s}$, but given the relatively long half-lives of the relevant transmutants, the results would not change if another flux was employed.

\section{Comparison of AISI $347 / 348$ with other 300 Series Stainless Steels}

As mentioned in the introduction, open literature data on the irradiation performance of AISI 348 is limited, with most data at relatively low exposures compared to the exposures envisaged in the current effort. ${ }^{1,2,3}$ There are, however, somewhat more published data on AISI 347, reaching both lower and higher exposures. ${ }^{5,6,7}$ 
The perceived primary advantage of AISI 348 stainless steel in the nuclear community has been its lower activation due to lower levels of easily activated, long-lived impurities, especially Co. However, after service in highly thermalized neutron spectra these steels are so radioactive that Co reduction does not really improve post-irradiation safety and handling.

Based on the results of examination of the very slight compositional differences between AISI 347 and AISI 348 and the accumulated experience on stainless steels leads to the conclusion that, with respect to void swelling, irradiation creep, and mechanical stability, the two steels are essentially identical. ${ }^{8,9}$ AISI 347 behaves well under irradiation without any greatly significant differences from other 300 series steels, especially AISI 316, which is often employed in LWR and liquid metal reactor (LMR) nuclear environments. These three steels also are less prone than AISI 304 to form martensite and radiationinduced ferrite during deformation.

All of the 300 series steels in the temperature range of current interest are very prone to radiation-induced segregation to sinks, giving rise to phase instabilities that produce radiation-stable $\mathrm{Ni}$ and Si-rich precipitates such as gamma-prime and G-phase, in addition to various compositionally modified carbide phases. ${ }^{9} \mathrm{Ni}$ is the major source of both helium and hydrogen generation via transmutation at relatively high exposures, especially in highly thermalized spectra such as those found in ATR and HFIR. ${ }^{10,11,12}$

In the 300 series steels operating in highly thermalized neutron spectra characteristic of ATR, the Mn will strongly transmute to Fe. ${ }^{13}$ Normally, this transformation is not a concern in 300 series alloys since the Mn level is usually low, at $1-2 \%$, and its loss does not severely impact the stability of the austenite phase.

A second-order consequence affects the stability of $\mathrm{MnS}$ precipitates in older, not-so-pure heats of steel. Since very stable $\mathrm{MnS}$ precipitates are transformed into not so stable FeS, this transformation releases previously sequestered $\mathrm{S}$ and detrimental halides $(\mathrm{F}, \mathrm{Cl})$ into the matrix. This process has been proposed as one contribution to irradiation-assisted stress corrosion cracking observed in 300 series steels in water-cooled reactors. ${ }^{14,15}$

The stability of MnS precipitates is also strongly influenced by a phenomenon designated the Inverse-Kirkendall effect. ${ }^{16}$ This is a radiation-driven process that strongly segregates elements which diffuse by a vacancy exchange mechanism. Slower-diffusing species segregate by default at all sink surfaces (grain boundaries, dislocations, Frank loops, precipitates) with faster-diffusing species being depleted at the sink surface. In a Fe-Cr-Ni-Mn base alloy, $\mathrm{Mn}$ is the fastest diffusing species followed by $\mathrm{Cr}$ and $\mathrm{Fe}$, with $\mathrm{Ni}$ being the slowest. This provides another driving force to dissolve $\mathrm{MnS}$ by pumping $\mathrm{Mn}$ away from $\mathrm{MnS}$ precipitates that are also becoming rich in Fe via transmutation. ${ }^{14,15}$

In the modern production of steels, the concentration of $\mathrm{S}$ and various halides are usually much lower, so the problem of MnS dissolution is not as pronounced. As will be shown later, the Inverse Kirkendall effect strongly changes the composition at grain boundaries with some potential consequences of concern to the current study.

There is additional transmutation of $\mathrm{Cr}$ to produce small amounts of $\mathrm{V}$, which leads to a modification of carbide composition, but no identifiable metallurgical consequences or property changes have been observed, especially in alloys already containing measurable amounts of $\mathrm{V}^{13}$ The percentage loss of $\mathrm{Cr}$ from the matrix is relatively small and insignificant; therefore it probably can be ignored.

In general, however, none of the 300 series steels experience severe problems arising from transmutation other than the possibility of higher void swelling levels in response to the large $\mathrm{He}$ and $\mathrm{H}$ generation in highly thermalized neutron spectra, especially at the higher boundaries of the dpa and temperature range defined as relevant to this study. ${ }^{9}$ 
As explained in the next several sections, it cannot be confidently asserted that XM-19 will also be relatively unaffected by transmutation, since its desirable properties arise from its rather unique composition compared to that of other 300 series steels.

\subsection{Advantages of XM-19 (Nitronic 50) Stainless Steel}

XM-19 has superior features that make it attractive for non-nuclear applications, including superior corrosion resistance, higher yield strength and ductility, and the ability to absorb a very large amount of deformation over a wide range of temperatures without forming martensite or magnetic phases.

The compositional specifications of XM-19 allow some range of variation. In this study the assumed composition was Fe-22Cr-5Mn-13Ni-3Mo-0.3Nb-0.4N-1.0Si-0.3V-0.04P-0.06C. However, variations within the specification ranges will not substantially alter the conclusions of the report.

While easily-dissolved interstitial impurity carbon is normally viewed as being an effective solid-solution strengthening agent, there are practical limitations on the carbon level arising from considerations of phase stability and grain boundary sensitization. Compared to various 300 series steels the most important compositional feature of XM-19 is the relatively high level of nitrogen.

Nitrogen is a much more effective interstitial impurity in providing structural strength, but it is relatively insoluble compared to carbon, especially in nickel-containing alloys. In $316 \mathrm{LN}$, for example, the $\mathrm{N}$ level is generally lower by a factor of 3-4 compared to that of XM-19, but has induced measurable increases in strength.

Excess undissolved nitrogen in steel will lead to cavities and undesirable precipitates such as $\mathrm{Cr}_{2} \mathrm{~N}$ during fabrication. However, there is a high probability that undissolved $\mathrm{N}$ will also promote earlier and larger amounts of void swelling during irradiation by acting as a stabilizing gas for void embryos, similar to the role exerted by $\mathrm{He}, \mathrm{H}$, and $\mathrm{O}$.

$\mathrm{Ni}, \mathrm{P}$ and $\mathrm{C}$ all tend to reduce nitrogen solubility in austenite, while $\mathrm{Cr}, \mathrm{Mo}, \mathrm{Si}$ and $\mathrm{V}$ and $\mathrm{Mn}$ act to increase the solubility of nitrogen. ${ }^{17} \mathrm{Cr}$ and $\mathrm{Mn}$ are the major contributors to nitrogen solubility, however, and XM-19 has higher than ordinary amounts of both elements.

Mn also promotes austenite stability, aids in flow during casting, and sequesters $\mathrm{S}$ and halide impurities, among other benefits. Very importantly, however, Mn strongly increases the stacking fault energy and thereby promotes work hardening, leading to enhanced ductility. There are practical limitations to the addition of manganese, with 5 to $6 \%$ selected as optimum for this application.

Both $\mathrm{Nb}$ and $\mathrm{V}$ will act to sequester $\mathrm{C}$ in various carbide phases, a process that usually delays the onset of nickel silicide precipitation.

Considering the foregoing discussion, the major compositional attributes of XM-19 that differ from those of 300 series alloys are associated with synergistic strengthening by dissolved Ni and work hardening by $\mathrm{Mn}$. The prospect of maintaining these attributes are the focus of the following discussion.

\subsubsection{Influence of Radiation on Properties of XM-19}

Before considering the influence of transmutation some statements can be made concerning the potential radiation performance of XM-19. It should be noted that the Si level is twice that of most 300 series steels used in reactor service ( $\sim 1.0$ vs. $\sim 0.5 \%)$. This increased silicon level will lead to an initial delay in the onset of swelling but will strongly foster enhanced formation of nickel silicide phases, especially gamma prime, in the temperature range of interest. ${ }^{18,19,20}$ 
The deliberate addition of $\mathrm{V}$ will tend to diminish somewhat the impact of $\mathrm{Cr}$ to $\mathrm{V}$ transmutation, and the levels of $\mathrm{P}$ and $\mathrm{C}$ are just about right to restrain the onset of swelling in the relevant temperature range. ${ }^{9}$ The use of $\mathrm{Nb}$ and $\mathrm{V}$ to form matrix carbide precipitates also works to minimize the deleterious influence of chromium carbides forming on and sensitizing grain boundaries. ${ }^{21}$

While the $13 \%$ nickel level is higher than that of AISI 348 at $11 \%$, the increased generation of $\mathrm{He}$ and $\mathrm{H}$ will increase in direct proportion of 13/11. Ordinarily, this increase would not be considered significant, adding incrementally $(\sim 18 \%)$ to already rather large gas generation rates. For the purposes of this study, however, it is not thought to be prudent to overlook this enhanced gas generation.

The increased amount of $\mathrm{Ni}$, working with the larger Si level, will induce a much greater level of radiation-induced phase instability. Therefore, before any solid transmutation is considered, it is already clear that this alloy will be somewhat more immune to problems associated with carbide formation on boundaries, but will be more vulnerable to the impact of nickel silicide phases.

\subsubsection{Influence of Transmutation on the Composition of XM-19}

As shown in Figure 1, the transmutation of XM-19 will produce a significant amount of both helium and hydrogen in ATR. Most of these gases are generated by Ni, initially by high energy neutron reactions. But the isotopic balance of $\mathrm{Ni}$ is changed strongly by thermal neutrons, producing the long-lived radioactive isotope $\mathrm{Ni}-59$, which in turn leads to very large increases in the generation rate of both gases. The $14 \mathrm{~N}(\mathrm{n}, \mathrm{p}) 14 \mathrm{C}$ reaction also generates $\mathrm{H}$, but this reaction is not a primary contributor compared to the various Ni reactions. Note that $\mathrm{H}$ is initially formed at higher rates (see Figure 1), but as Ni-59 is formed from $\mathrm{Ni}-58$ in this highly thermalized neutron spectrum that $\mathrm{He}$ is produced at higher rates than $\mathrm{H}$.

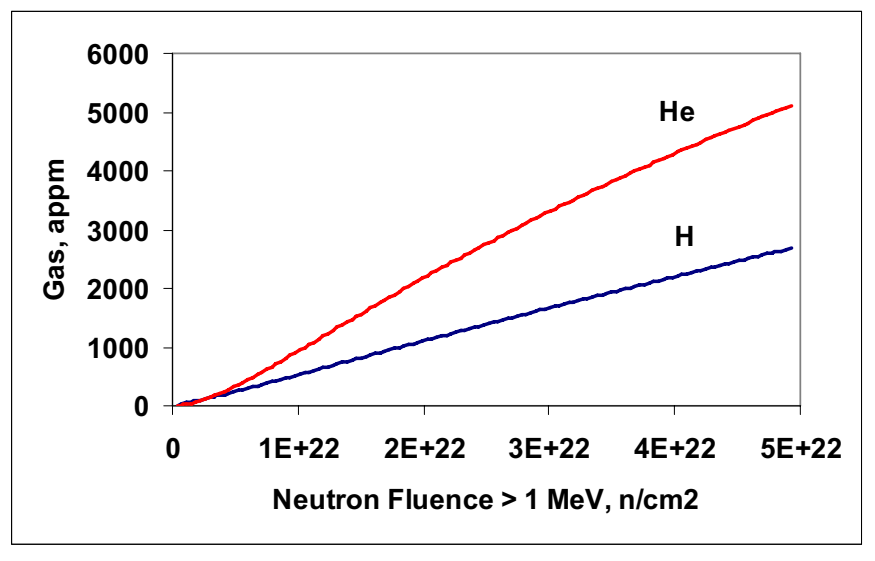

Figure 1. Generation of high levels of helium and hydrogen in XM-19 as a function of neutron exposure in ATR.

Helium in XM-19 reached 4,300 appm at the maximum fluence limit of $4 \times 10^{22} \mathrm{n} / \mathrm{cm}^{2}, \mathrm{E}>1 \mathrm{MeV}$ and generated hydrogen reaches $\sim 2,200 \mathrm{appm}$. At these levels, the alloy is becoming a gas-modified alloy whose properties need to be carefully assessed.

Helium is relatively immobile and trapped in the alloy but the hydrogen is more diffusive. While conventional wisdom dictates that the hydrogen will diffuse out of the steel, it was recently shown that the hydrogen is also trapped when there is a high density of helium-nucleated bubbles or voids. ${ }^{22}$ Even more importantly, in a water-cooled reactor there are many other sources of hydrogen and this non-transmutant hydrogen is also trapped at very high levels in cavities. ${ }^{22}$ In a publication by Thomas and Beeston, ${ }^{23}$ AISI 348 at $11 \% \mathrm{Ni}$ was shown to develop very high densities of voids or bubbles after irradiation to 33 to 39 dpa at $350^{\circ} \mathrm{C}$ in ATR. At that time it was assumed that the bubbles were pressurized only by helium. 
When compared to AISI 348, however, the gas generation issue in XM-19 is slightly greater than already experienced in ATR operation, being on the order of an $18 \%$ increase. Ordinarily this would be considered to be of only second-order influence, but perhaps not in this case.

There are relatively small to insignificant transmutation-induced changes in the contents of $\mathrm{Mo}, \mathrm{Si}$, $\mathrm{Nb}, \mathrm{Cr}, \mathrm{N}$, and $\mathrm{C}$. These changes are not thought to be significant in assessing the impact on phase stability, mechanical properties, irradiation creep, and void swelling of XM-19 alloy. Fe changes the most, rising from 55 to $59 \%$ at $5 \times 10^{22} \mathrm{E}>1.0 \mathrm{MeV}$ as a result of $\mathrm{Mn}$ transmutation. $\mathrm{V}$ increases from 0.3 to $0.7 \%$ over this interval, and there may or may not be consequences on phase stability as a result.

However, the issue of Mn transmutation cannot be so easily dismissed. Note in Figure 2 that $\mathrm{Mn}$ decreases strongly with accumulated exposure, reaching a loss of $\sim 75 \%$ of the original at the maximum target exposure of $4 \times 1022 \mathrm{n} / \mathrm{cm}^{2}, \mathrm{E}>1 \mathrm{MeV}$. The impact of such a large decrease in Mn on nitrogen solubility cannot be confidently ignored.

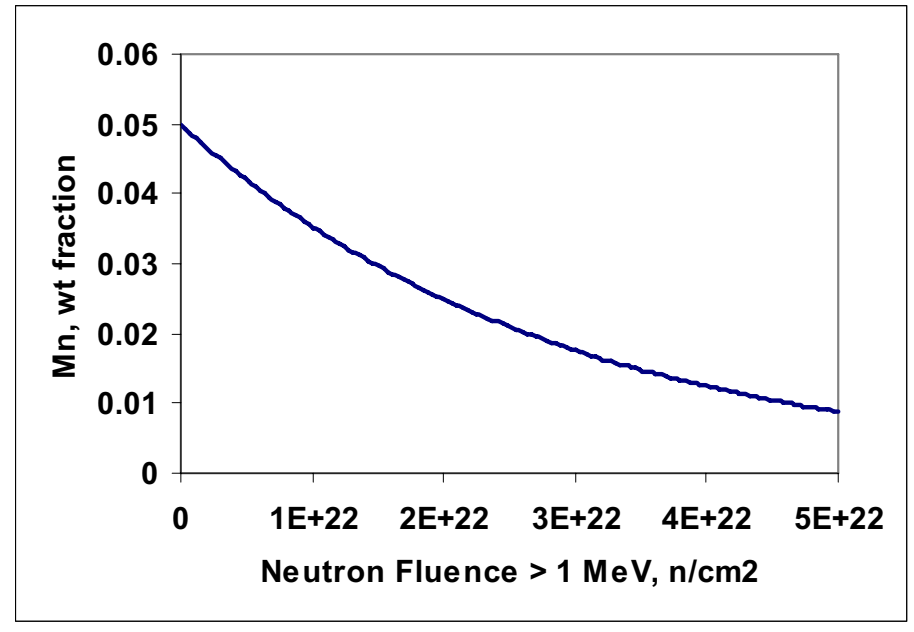

Figure 2. Decline in Mn content in XM-19 with accumulated neutron exposure in ATR.

It seems reasonable to assume that a continually increasing supersaturation of nitrogen with unpredictable consequences on alloy phase stability and dimensional stability will develop. In particular, increased dimensional instability may arise from acceleration of void swelling as a result of the combined action of $\mathrm{He}, \mathrm{H}$, and $\mathrm{N}$ to pressurize radiation-driven cavities.

In addition there might be a compounding of this phenomenon arising from the Inverse Kirkendall effect discussed earlier. At grain boundaries especially, it has been demonstrated that $\mathrm{Mn}$ and then $\mathrm{Cr}$ will be strongly depleted with primarily $\mathrm{Ni}$ increasing at the boundary to make up the difference. ${ }^{24,25,26,27,28,29,30}$ In a $\mathrm{Fe}-\mathrm{Cr}-\mathrm{Mn}$ alloy without $\mathrm{Ni}$, grain boundaries quickly turn to ferrite as $\mathrm{Mn}$ moves away. Increasing $\mathrm{Ni}$ at the boundary via the Inverse Kirkendall effect will act to further drive $\mathrm{N}$ from solution in the vicinity of the boundary. Furthermore, increasing Ni will also lead to higher local generation rates of $\mathrm{He}$ and $\mathrm{H}$ at the boundary.

It is conceivable that the combined effects of Mn reduction via transmutation and Inverse Kirkendall, both acting to release $\mathrm{N}$, when combined with increased $\mathrm{He}$ and $\mathrm{H}$, will act to coat the grain boundaries with a near-continuous film of gas bubbles. Such a development is not unprecedented and would severely weaken the alloy during deformation. In this context the $18 \%$ increase in $\mathrm{He}$ and $\mathrm{H}$ generation rates might be a significant contributor to alloy degradation. 
An example of such matrix development of gas-filled cavities and especially grain bubble boundary coating in an ordinary 300 series alloy without $\mathrm{Ni}$ addition is shown in Figure $3 .{ }^{31}$ Note that these micrographs were taken in a specimen irradiated at $70 \mathrm{dpa}$ and $350^{\circ} \mathrm{C}$, almost the exact irradiation condition specified as the upper limit of the current study, but here the nickel level and thermal neutron flux are lower than the XM-19 case and there is no nitrogen. The component from which this specimen was derived was showing a very high level of intergranular failure and contained high amounts of $\mathrm{H}$ and He. ${ }^{32}$ Hydrogen on grain boundaries is well known to not be conducive to continued integrity of grain boundaries during deformation.

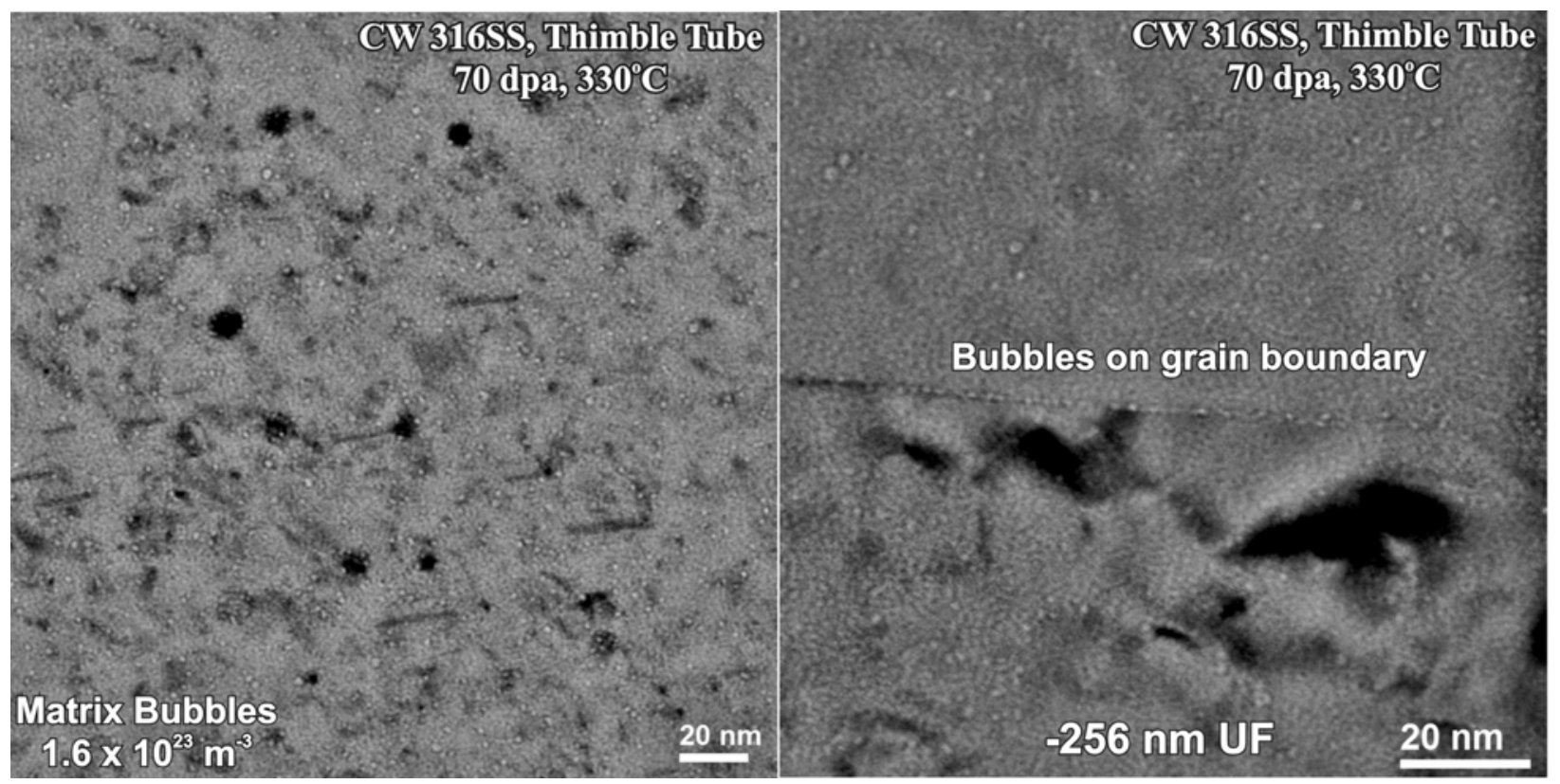

Figure 3. Gas-filled bubbles observed by electron microcopy in cold-worked 316 stainless steel after irradiation in a commercial PWR to $\sim 70 \mathrm{dpa}$ at $350^{\circ} \mathrm{C} .{ }^{31}$ 


\section{CONCLUSIONS AND RECOMMENDATIONS}

While most 300 series alloys will meet the required ATR conditions as well as AISI 348 has served, it cannot be confidently assumed that XM-19 can be substituted without prior qualification in a radiation test. Not only will strong transmutation of $\mathrm{Mn}$ to Fe reduce the ductility and strength advantages provided by the higher initial Mn content of XM-19, the extensive loss of Mn will also release from solution much of the $\mathrm{N}$ upon which the higher strength of XM-19 depends. In addition, the combined influence of the transmutation and Inverse Kirkendall processes may lead to gas-bubble-covered grain boundaries, producing a very fragile alloy after significant irradiation has been accumulated. While this scenario is somewhat speculative, there are no data to refute the possibility and it should be investigated.

However, rather than use XM-19 to replace hard to obtain AISI 348, it is recommended that serious consideration be given to the use of AISI 347 as a substitute for AISI 348. These alloys are essentially indistinguishable with respect to void swelling, irradiation creep, and mechanical property changes. Whereas AISI 348 is usually chosen for nuclear service in order to reduce the overall radioactivation arising from relatively small amounts of highly transmutable elements such as Co, these elements have very little effect on the radiation performance of the steel. In the proposed application, however, the activity induced in this highly thermalized spectrum to large doses (10 to $50 \mathrm{dpa}$ ) will be overwhelmed by the activation arising from the major steel components $\mathrm{Fe}, \mathrm{Cr}$, and especially $\mathrm{Ni}$. The mechanical properties, irradiation creep, and void swelling behavior of the two steels should be practically indistinguishable.

It is also recommended that XM-19 be included in ATR or another thermal reactor to assess the validity of the scenario advanced in this assessment. The amount of material can be very small, perhaps even a handful of TEM microscopy disks. The most important criterion is that substantial transmutation be induced to test the validity of mechanisms discussed in this report. If only one temperature condition is available in the test matrix, the upper range temperature should be chosen to maximize the influence of the Inverse Kirkendall effect. 


\section{REFERENCES}

1. J. E. Irvin, A. L. Bement and R. G. Hoagland, "The Combined Effects of Temperature and Irradiation on the Mechanical Properties of A austenitic Stainless Steels," Flow and Fracture of Metals and Alloys in Nuclear Environments, ASTM STP 380, 1965, pp. 236-250.

2. J. J. Holmes, R. E. Robbins and A. J. Lovell, "Postirradiation Tensile Behavior of 300 Series Stainless Steels," Irradiation Effects in Structural Alloys for Thermal and Fast Reactors, ASTM STP 475, 1969, pp. 371-389.

3. J. E. Irvin and A. L. Bement, "Nature of Radiation Damage to Engineering Properties of Various Stainless Steel Alloys," Effects of Radiation on Structural Materials, ASTM STP 426, 1967, pp. 278-327.

4. Private confidential communications between Frank Garner and two engineers working in different commercial light water reactor programs. One individual stated that XM-19 has been used as "a replacement material in tie rods and nuts for recent repairs of BWR core shrouds. Other applications include reactor coolant pump shafts and/or other bolting applications in the RCS." The second individual said that the "primary application of the Nitronic material is for thermal shield attachment bolts (replacement) - so conditions are what is experienced outside core barrel. No data beyond material certs (everybody wants to fix the problem but nobody wants to pay for finding what caused the problem). I am aware of only one other application (washers in upper internals region).Like I said, it is not used much - only a handful of plants."

5. W. R. Martin and J. R. Weir, "The Effect of Irradiation Temperature on the Post-Irradiation Stress-Strain Behavior of Stainless Steel," Flow and Fracture of Metals and Alloys in Nuclear Environments, ASTM STP 380, 1965, pp. 251-268.

6. H. J. Busboom, G. C. McClellan, W. L. Bell and W. K. Appleby, "Swelling of Types 304 and 316 stainless steel irradiated to $8 \times 10^{22} \mathrm{n} / \mathrm{cm}^{2}$," General Electric Company Report GEAP-14062, 1975 .

7. J. S. Watkin, "Dependence of Void Swelling on the Electron Vacancy Concentration," Irradiation Effects on the Microstructure and Properties of Metals, ASTM STP 611, 1976, pp. 270-283.

8. F. A. Garner and H. R. Brager, "The Influence of Mo, Si, P, C, Ti, Cr, Zr and Various Trace Elements on the Neutron-Induced Swelling of AISI 316 Stainless Steel," J. of Nucl. Mater., 155-157 (1988), pp. 833-837.

9. F. A. Garner, Chapter 6: "Irradiation Performance of Cladding and Structural Steels in Liquid Metal Reactors," Vol. 10A of Materials Science and Technology: A Comprehensive Treatment, VCH Publishers, 1994, pp. 419-543.

10. L. R. Greenwood and F. A. Garner, "Hydrogen Generation Arising from the 59Ni (n,p) Reaction and its Impact on Fission-Fusion Correlations," J. of Nucl. Mater., 233-237 (1996) 1530-1534.

11. F. A. Garner, B. M. Oliver and L. R. Greenwood, "The Dependence of Helium Generation Rate on Nickel Content of Fe-Cr-Ni Alloys Irradiated at High dpa Levels in Fast Reactors," J. of Nucl. Mater., 258-263 (1998), pp. 1740-1744.

12. F. A. Garner, L. R. Greenwood and B. M. Oliver, "A Reevaluation of Helium/dpa and Hydrogen/dpa Ratios for Fast Reactor and Thermal Reactor Data Used in Fission-Fusion Correlations," Effects of Radiation on Materials: $18^{\text {th }}$ International Symposium, ASTM STP 1325, R. K. Nanstad, M. L. Hamilton, F. A. Garner and A. S. Kumar, Eds., American Society of Testing and Materials, 1999, pp. 794-807.

13. J. F. Bates, F. A. Garner and F. M. Mann, "The Effects of Solid Transmutation Products on Swelling in AISI 316 Stainless Steel,” J. of Nucl. Mater., 103 and 104 (1981), p. 999. 
14. F. A. Garner, L. R. Greenwood and H. M. Chung, "Irradiation-Induced Instability of MnS Precipitates and Its Possible Contribution to IASCC in Light Water Reactors," Proceedings Eighth International Symposium On Environmental Degradation of Materials in Nuclear Power SystemsWater Reactors, Amelia Island, Florida, Aug 10-14, 1997, pp. 857-860.

15. H. Chung and F. A. Garner, "Radiation-Induced Instability of MnS Precipitates and Its Possible Consequences on Irradiation-Assisted Stress Corrosion Cracking of Austenitic Stainless Steels," Effects of Radiation on Materials: $18^{\text {th }}$ International Symposium, ASTM STP 1325, R. K. Nanstad, M. L. Hamilton, F. A. Garner and A. S. Kumar, Eds., American Society of testing and Materials, 1999, pp. 647-658.

16. A. D. Marwick, R. C. Pillar, and P. M. Sevill, J. Nucl. Mater., 83,(1979) 35-41.

17. K. J. Irvine, D. T. Llewllyn and F. B. Pickering, J. of Iron and Steel Institute, Vol. 199, 1961, p. 153.

18. H. R. Brager and F. A. Garner, "Swelling as a Consequence of Gamma Prime (c') and $\mathrm{M}_{23}(\mathrm{C}, \mathrm{Si})_{6}$ Formation in Neutron Irradiated 316 Stainless Steel," J. of Nucl. Mater. 73 (1978), pp. 9-19.

19. W. J. S. Yang, H. R. Brager and F. A. Garner, "Radiation-Induced Phase Development in AISI 316," in Proceedings of AIME Symposium on Irradiation Phase Stability, Pittsburgh, Pennsylvania, (October 5-9, 1980), p. 257.

20. D. J. Mazey, D. R. Harries and J. A. Hudson, "The Effects of Silicon and Titanium on Void Swelling and Phase Stability in 12Cr-15Ni Austenitic Alloys Irradiated with $46 \mathrm{MeV}$ Nickel Ions," J. Nucl. Mater., 89 (1980) 155-181.

21. P. Scott, “A Review of Irradiation-Assisted Stress Corrosion Cracking,” J. Nucl. Mater., 211 (1994) 101.

22. F. A. Garner, E. P. Simonen, B. M. Oliver, L. R. Greenwood, M. L. Grossbeck, W. G. Wolfer and P. M. Scott, "Retention of Hydrogen in FCC Metals Irradiated at Temperatures Leading to High Densities of Bubbles or Voids," J. Nucl. Mater., 356 (2006) 122-135.

23. L. E. Thomas and J. M. Beeston, "The Microstructure of Neutron Irradiated Type-348 Stainless Steel and its Relation to Creep and Hardening," J, Nucl, Mater., 107 (1982) 159-2167.

24. F. A. Garner and H. L. Brager, "Neutron-Induced Swelling of Fe-Mn and Fe-Cr-Mn Austenitic Alloys," Effects of Radiation on Materials: Thirteenth International Symposium (Part 1) Radiation-Induced Changes in Microstructure, ASTM STP 955, F. A. Garner, N. H. Packan and A. S. Kumar, Eds., ASTM, Philadelphia, PA, 1987, pp. 195-206.

25. F. A. Garner, H. R. Brager, D. S. Gelles and J. M. McCarthy, "Neutron Irradiation of Fe-Mn, $\mathrm{Fe}-\mathrm{Cr}-\mathrm{Mn}$ and Fe-Cr-Ni Alloys and an Explanation of Their Differences in Swelling Behavior," J. of Nucl. Mater., 148 (1987), pp. 294-301.

26. J. M. McCarthy and F. A. Garner, "Phase Instabilities in Irradiated Simple Fe-Cr-Mn Low Activation Alloys," J. of Nucl. Mater., 155-157 (1988), pp. 877-882.

27. F. A. Garner and J. M. McCarthy, "An Assessment of Fe-Cr-Mn Austenitic Alloys for Fusion Service Using Fast Reactor Irradiation," in Reduced Activation Materials for Fusion Reactors, ASTM STP 1047, R. L. Klueh, D. S. Gelles, M. Okada, and N. H. Packan, Eds., American Society for Testing and Materials, Philadelphia, 1990, pp. 19-29.

28. H. Takahashi, F. A. Garner, H. Itoh, B. Hu and S. Ohnuki, "The Behavior of Solute Segregation and Void Formation in Fe-Cr-Mn Steel Under Electron Irradiation," Effects of Radiation on Materials: Thirteenth International Symposium (Part 1) Radiation-Induced Changes in Microstructure, ASTM STP 955, F. A. Garner, N. H. Packan and A. S. Kumar, Eds., ASTM, Philadelphia, Pennsylvania, 1987, pp. 268-278. 
29. F. A. Garner, H. R. Brager and H. Takahashi, "Neutron-Induced Swelling of Model Fe-Cr-Mn-Ni Alloys and Commercial Manganese-Stabilized Steels," J. of Nucl. Mater., 179-181 (1991) 633-636.

30. H. Takahashi, S. Ohnuki, F. A. Garner and Hu Ben-fu, "The Effects of Nickel on Microchemical Development and Microchemical Changes in Neutron-Irradiated Fe-Cr-Mn Based Steels," Proceedings 15th International Symposium on the Effects of Radiation on Materials, ASTM STP 1125, 1992, R. E. Stoller, A. S. Kumar and D. S. Gelles, Eds., pp. 969-978.

31. D. J. Edwards, E. P. Simonen, S. M. Breummer and P. Efsing, "Microstructural Evolution in Neutron-Irradiated Stainless Steels: Comparison of LWR and Fast-Reactor Irradiations," Proceeedings of $12^{\text {th }}$ International Conference on Environmental Degradation of Materials in Nuclear Power Systems - Water Reactors, 2005, pp. 419-428.

32. J. Connermann, R.Shogan, K. Fujimoto, T. Yonezawa and Y. Yamaguchi, "Irradiation Effects in a Highly Irradiated Cold Worked Stainless Steel Removed from a Commercial PWR,” ibid. ref. 31, pp. 277-287. 